\title{
REVIEW
}

\section{Vascular tone in heart failure: the neuroendocrine-therapeutic interface}

\author{
John G F Cleland, Celia M Oakley
}

Impaired cardiac function is of course the primary problem in heart failure, but it is also the stimulus to activation of several integrated neuroendocrine systems. Activation of these neuroendocrine systems at first seems to have important beneficial effects for the failing circulation-maintaining cardiac output, blood pressure, blood flow to essential organs, and the glomerular filtration rate. Prolonged or extreme neuroendocrine activation, however, may prove deleterious.

The advent of effective diuretics had a tremendous impact on the management of patients with heart failure. Then, in the absence of a cure for the primary problem, thoughts returned to agents that either increased the force of myocardial contraction (inotropic agents) or reduced the load on the failing heart (vasodilator agents). Both modes of treatment have proved effective in improving haemodynamic function in the short term. Neither therapeutic intervention has yet been established as having beneficial effects for long term treatment of heart failure.

A fourth group of agents was added to the treatment of heart failure in the $1980 \mathrm{~s}$. The angiotensin converting enzyme (ACE) inhibitors have showed not only their ability to improve symptoms and exercise performance, but also to reduce mortality and possibly slow the rate of decline in ventricular function. In the 1990s their use is certainly going to increase. These agents are more than just another group of vasodilator agents. Their effects on neuroendocrine activity seem to be integral to their success. A review of the interaction between neuroendocrine variables and vasodilator therapy is timely.

\section{Historical perspectives}

Before the 1940s theories on the nature of the circulatory disorder in heart failure abounded, but the means of treating the condition were limited. The advent of cardiac catheterisation, of methods of measuring regional blood flow, and, finally, of non-invasive measures of cardiovascular function has contributed to better understanding of the interplay between the failing heart and the abnormal circulation that it still supports.

The introduction of mercurial diuretics in the $1920 \mathrm{~s}$, thiazides in the $1950 \mathrm{~s}$, and loop diuretics in the 1960s all made substantial contributions to the alleviation of symptoms while leading indirectly to some deleterious haemodynamic and neuroendocrine effects.

The relation between cardiac output and venous pressure in heart failure was described at the Hammersmith Hospital in the 1940s, and Wood recognised that increased systemic vasoconstriction was one of the hallmarks of heart failure. ${ }^{2}$ These ideas were brought together by Braunwald in the 1960 s, who integrated the concepts of altered pre-load, after-load, and myocardial contractility and promoted the theoretical rationale for vasodilator therapy for heart failure. ${ }^{3}$

However, the concept of reducing vascular tone in the treatment of heart failure is much older. Osler (1892) used nitroglycerine ${ }^{4}$ and Savill (1936) suggested sympathectomy ${ }^{5}$ as a treatment for intractable heart failure. These ideas gained substance in the 1950 s, with the use of ganglion blocking agents ${ }^{6}$ and nitrates. ${ }^{7}$ Since then, nitrates have achieved a lasting place in the management of pulmonary oedema. The use of phentolamine in the 1970s ushered in the "modern" era of vasodilator therapy. ${ }^{8}$ However, despite all the theoretical considerations, until the appearance of ACE inhibitors in the 1980 s, vasodilator agents achieved no firm practical role in the management of chronic heart failure.

\section{Neuroendocrine consequences of heart failure}

The circulation responds both to changes in volume and to changes in pressure. Those reflexes which depend on pressure receptors (that is, carotid, aortic arch, and renal) seem to work fairly normally in heart failure, ${ }^{910}$ with reduction in arterial wall tension activating the sympathetic nervous and renin-angiotensinaldosterone systems. Though such reflexes may be slightly blunted they work in a directionally normal sense.

In contrast, volume dependent reflexes (that is, of the atria and great veins) seem to be markedly blunted or directionally abnormal. The diuresis that can be elicited by atrial distention is reduced. Although atrial natriuretic peptide is increase ${ }^{11}$ its renal effects are considerably reduced in heart failure. Plasma concentrations of arginine vasopressin, which would normally be suppressed during atrial distention, are increased.

Animal models of heart failure suggest that initial activation of the sympathetic nervous 
and renin-angiotensin systems results in fluid retention and vasoconstriction. ${ }^{12}$ If the primary myocardial insult is not too severe, fluid retension causes blood volume expansion with a restoration of arterial pressure, and as this occurs activation of the neuroendocrine systems wanes. This is consistent with observations in patients developing heart failure after myocardial infarction..$^{13}$ However, if the cardiac insult is severe enough haemodynamic equilibrium cannot be achieved. This may manifest itself in several ways; cardiogenic shock will result from an excessive fall in stroke output or pulmonary oedema from an excessive rise in left atrial pressure. Most patients with chronic heart failure are already receiving diuretics which prevent the patient from attaining haemodynamic equilibrium; therefore activation of vasoconstrictor neuroendocrine systems is maintained. Diuretics, by reversing fluid retention, reveal the underlying activation of the reninangiotensin system. High plasma concentrations of renin, angiotensin II, noradrenaline, and atrial natriuretic peptide are also important and indicate a poor prognosis. ${ }^{14}{ }^{15} \mathrm{High}$ concentrations of catecholamine and angiotensin $\mathrm{II}^{16}$ may be directly cardiotoxic as well as adding to a downward spiral of increasing vascular resistance, neuroendocrine activation, and deteriorating haemodynamic function. However, it is not certain whether neuroendocrine activation itself makes a contribution to increasing mortality or is just a marker of severity. The demonstration that normal concentrations of plasma renin with high sympathetic activity may be exchanged for the converse by diuretics ${ }^{17}$ illustrates the absence of any simple relation between neuroendocrine activation and prognosis.

\section{"Conventional" vasodilators}

Despite many trials on vasodilators there is little evidence that they are effective in improving symptoms and exercise performance in chronic heart failure. ${ }^{18-20}$ Although the combination of nitrates and hydralazine did reduce mortality in one study the effect was modest. ${ }^{21}$ Some studies have purported to show benefit with each of these agents, but all are flawed because of inadequate control data, changes in diuretic dose, or misrepresentation of results. ${ }^{22} 23$ There is now ample evidence that "conventional" vasodilators are inferior to $\mathrm{ACE}$ inhibitors, and of the reasons for this.

As heart failure develops, vascular resistance increases; but this does not happen equally in all vascular beds. Blood flow to the limbs and brain is reduced at rest in more severe cases only, whereas renal blood flow declines from an early stage. During exercise blood flow to the exercising muscle is reduced-and flow to the kidney is reduced even more. Conventional vasodilators are not "intelligent". They reduce vascular resistance, but not selectively. They increase blood flow to non-essential organs, such as the skin, and do not increase the use of oxygen by the limbs during exercise despite increasing limb blood flow. ${ }^{24} 25$ Thus blood seems to be shunted past metabolically active muscle.

Management of the patient with acute pulmonary oedema according to the classic principles of reduction of pre and after load is effective, but these same haemodynamic concepts may be less appropriate in the management of chronic heart failure. Changes in skeletal muscle related to deconditioning, ${ }^{26}$ intracellular deficits of potassium, ${ }^{27}$ or excesses of sodium ${ }^{27}$ may also be important therapeutic targets in chronic heart failure, when the underlying cardiac abnormality itself cannot be corrected.

Clearly there is a big difference between the regional distribution of the cardiac output "driven" by the heart and output "led" by reducing the vascular resistance.

Tolerance to vasodilator agents: role of neuroendocrine activation

Tolerance to vasodilators may be caused by metabolic changes in the vascular wall, as in the case of nitrates, leading to a loss of effect on vascular smooth muscle. In many instances, however, neuroendocrine and metabolic (mal)adaptations may be even more important, or the sole cause.

Administration of the powerful vasodilators minoxidil and diazoxide to patients with heart failure results in immediate beneficial haemodynamic effects, but gross fluid retention rapidly supervenes. ${ }^{28} \mathrm{~A}$ similar phenomenon, milder in degree, probably occurs with other arteriolar dilators, due to a fall in arterial pressure, and hence renal perfusion pressure. Associated increases in the activities of the sympathetic nervous and renin-angiotensinaldosterone systems can further exacerbate renal sodium retention. ${ }^{28-30}$ Increasing the dose of diuretic to reverse fluid retention leads to greater neuroendocrine activation, which will further reverse the vasodilatation. Increases in angiotensin II and the fall in perfusion pressure can cause a paradoxical fall in renal blood flow, ${ }^{31}$ and create a vicious cycle of declining renal function and increasing diuretic requirements. Agents that reduce atrial pressure are likely to exacerbate fluid retention still further by reducing atrial natriuretic peptide-though patients with heart failure seem less responsive to atrial peptide, it is not entirely devoid of action.

The development of tolerance means that no true test of the therapeutic effects of chronic vasodilation in heart failure can be made with "conventional" vasodilators. Attempts have been made to reverse the effects of neuroendocrine activation induced by prazosin using spironolactone with unconfirmed success. ${ }^{32}$ Combining prazosin and captopril does not prevent fluid retention or improve the clinical response. ${ }^{33}$ The combination of a vasodilator with an atrial peptidase inhibitor is currently being evaluated.

\section{Angiotensin converting enzyme inhibitors}

ACE inhibitors have proven salutary effects on the symptoms and signs of heart failure, 
improve the "metabolic profile" of the patient, increase renal blood flow, may reduce arrhythmias and progressive ventricular dysfunction, and improve survival. ${ }^{34-36}$ Compared with "conventional" vasodilators the effects of ACE inhibitors on cardiac output are generally modest: their comparative therapeutic benefits are not. ${ }^{1737}$ Studies that suggest that ACE inhibitors exert their benefits by increasing effective oxygen delivery to the exercising limb, in contrast with "conventional" vasodilators, are flawed in their argument. ${ }^{38}$ Association does not equal causation. Increased exercise performance would be expected to lead to a more pronounced reduction in vascular resistance in response to the accumulation of vasodilating waste products in exercising muscle, which in turn will lead to increased blood flow. Improvements in blood flow during chronic therapy probably owe more to changes in vessel wall composition and the capacity of the vessel valve to respond to vasodilator stimuli rather than to simple direct vasodilatation.

\section{Neuroendocrine effects}

ACE inhibitors exert most of their effects by reducing angiotensin II. The inhibition of bradykinin stimulation and the effects on prostaglandins are of uncertain clinical significance. The immediate response to an ACE inhibitor is a reduction in the plasma concentrations of angiotensin II, aldosterone, noradrenaline, and atrial natriuretic peptide. ${ }^{39} 40$ Adrenaline and arginine vasopressin show little change unless hypotension is profound. ${ }^{41}$

Longer term inhibition of ACE results in continued supression of angiotensin II, aldosterone, and noradrenaline plus a decline in arginine vasopressin..$^{35}{ }^{36}$ Increases in renin and angiotensin II activity in response to diuretics, standing, and exercise are prevented. ${ }^{42}$ Suppression of aldosterone declines with time, a result of a rise in serum potassium concentration, which stimulates aldosterone secretion. This is a useful safeguard against severe hyperkalaemia during ACE inhibition. Plasma noradrenaline is suppressed in the supine position, but increases in response to standing, a normal reflex usually absent in patients with heart failure. ${ }^{42}$ The response to exercise is less clear, but for the same level of exercise sympathetic activation may be less. Arginine vasopressin is also reduced in the supine position but in response to diuretics, standing, and exercise, rises to pre-treatment concentrations. Atrial natriuretic peptide may also rise to pretreatment concentrations despite a continued fall in atrial pressure. ${ }^{43}$

\section{Metabolic effects}

ACE inhibitors share some of the problems of other vasodilators, namely hypotension and sodium retention when treatment starts. ${ }^{3944}$ The diuretic response to frusemide is impaired because of the fall in arterial pressure and glomerular filtration rate and the withdrawal of atrial natriuretic peptide ${ }^{40} 44$ if atrial pressure falls; but, in contrast with other vasodilators, angiotensin II, aldosterone, and sympathetic nervous activity are reduced so sodium retention is limited and does not persist.

Hypotension increases arginine vasopression and may actually cause an early fall in serum sodium, but long term controlled studies have not suggested any overall change. ${ }^{34}$ Potassium retention begins as soon as ACE inhibitors are started but is not reflected in a rise in serum potassium for days or even weeks. ${ }^{44}$ The potassium is retained in the depleted intracellular compartment ${ }^{45}$ but the serum potassium eventually rises as the pre-treatment total body potassium depletion is corrected. Potassium sparing diuretics, which may be needed in the early days or weeks of treatment, can, if continued, lead to dangerous hyperkalaemia. Spironolactone is most likely to give rise to problems for the reasons outlined above.

\section{Prediction of effect}

Just as there is a poor relation between clinical state and neuroendocrine activation, so activation of these systems is a poor predictor of response to an $\mathrm{ACE}$ inhibitor. ${ }^{46} \mathrm{~A}$ modest correlation has been noted between the initial haemodynamic effects and plasma renin, which is lost during long term follow up. The increase in plasma renin in response to the first dose of an ACE inhibitor may be a guide to long term efficacy. ${ }^{47}$

\section{Conclusion}

Although direct acting vasodilators might be expected to improve symptoms and exercise performance in heart failure, they have proved disappointing. Once again theoretical considerations have failed to work out in clinical practice. There is compelling evidence that their use in chronic heart failure leads to further neuroendocrine activation and that it is this which limits their therapeutic efficacy.

ACE inhibitors were introduced as a new class of vasodilator agent and once again medical serendipity seems to be operating. ACE inhibitors are more than mere vasodilator agents. Indeed their vasodilator actions may not even be a necessary part of their therapeutic effect. The reason for their efficacy remains to be established. Perhaps it is because they induce haemodynamic tolerance only infrequently. However, correction of intracellular electrolyte disturbances, changes in renal sodium and water handling, in the constitution of the vessel wall, and effects on cardiovascular sympathetic control may all contribute to the efficacy of these agents.

1 McMichael J. Circulatory failure studied by means of enous catheterisation. Adv Intern Med 1947;2:64-101. ood P. Disease of the heart and circulation. London: Eyre and Spottiswoode, 1950.

and Heart J 1965;27:1-16.

sler W. The principles and practice of medicine. New York, London: D Appleton, 1892:626-7.

Savill TD $A$ system of clinical medicine. London: Edward Arnold, 1936 . Hayward GW. Tetraethyl ammonium bromide in hyperten- 
7 Johnson JB, Gross JF, Hale E. Effects of sublingual administration of nitroglycerine in pulmonary artery pressure in patients with failure of the left ventricle. $N$ Engl J Med 1957;257:1114-7.

8 Majid PA, Sharma B, Taylor SH. Phentolamine for vasodilator treatment of severe heart failure. Lancet 1971;ii:719-24.

9 Harris P. Congestive cardiac failure: central role of the arterial blood pressure. Br Heart J 1987;58:190-203.

10 Cleland JGF, Dargie HJ. Heart failure, renal function and angiotensin converting enzyme inhibitors. Kidney Int angiotensin converting en
1987;31(suppl 20):S-220-8.

11 Richards AM, Cleland JGF, Tonolo G, McIntyre GD, Leckie BJ, Dargie HJ, et al. Plasma a natriuretic peptide in Leckie BJ, Dargie HJ, et al. Plasma a natriure
cardiac impairment. BMJ 1986;293:409-12.

12 Watkins L Jr, Burton JA, Haber E, Cant JR, Smith FW, Barger AC. The renin-angiotensin-aldosterone system in congestive failure in conscious dogs. J Clin Invest 1976;57:1606-17.

13 McAlpine HM, Morton JJ, Leckie B, Rumley A, Gillen G, Dargie HJ. Neuroendocrine activation after acute myocardial infarction. Br Heart $J$ 1988;60:117-24

14 Swedberg K, Eneroth P, Kjekshus J, Wilhelmsen L. Hormones regulating cardiovascular function in patients with severe congestive heart failure and their relation to mortality. Circulation 1990;82:1730-6.

15 Dargie HJ, Cleland JGF, Leckie BJ, Inglis CG, East BW, Ford I. Relation of arrhythmias and electrolyte abnormalities to survival in patients with severe chronic heart failure. Circulation 1987;75(suppl IV):IV-98-107.

16 Kremer D, Lindop G, Brown WC, Morton JJ, Robertson JI. Angiotensin-induced myocardial necrosis and renal Angiotensin-induced myocardial necrosis and renal
failure in the rabbit: distribution of lesions and severity in failure in the rabbit: distribution of lesions and severity in
relation to plasma angiotensin II concentration and relation to plasma angiotensin II concentratio
arterial pressure. Cardiovasc Res 1981;15:43-6.

17 Bayliss J, Norell M, Canepa-Anson R, Sutton G, PooleWilson $P$. Untreated heart failure: clinical and neuroen docrine effects of introducing diuretics. Br Heart 1987;57:17-22.

18 Franciosa JA, Weber KT, Levine TB, Kinasewitz GT Janicki JS, West J, et al. Hydralazine in the long-term treatment of chronic heart failure: lack of difference from placebo. Am Heart J 1982;104:587-94.

19 Tan LB, Murray RG, Littler WA. Felodipine in patients with chronic heart failure: discrepant haemodynamic and clinical effects. Br Heart $J$ 1987;58:122-8.

20 Bayliss J, Norell MS, Canepa-Anson R, Reid C, PooleWilson P, Sutton G. Clinical importance of the reninangiotensin system in chronic heart failure: double blind angiotensin system in chronic heart failure: double blind
comparison of captopril and prazosin. BMJ comparison of

21 Cohn JN, Archibald DG, Ziesche S, Franciosa JA, Harston WE, Tristani FE, et al. Effect of vasodilator therapy on mortality in chronic congestive heart failure. Results of Veterans Administration Co-operative Study. $N$ Engl $J$ Med 1986;314:1547-52.

22 Leier CV, Huss P, Magorien RD, Unverferth DV Improved exercise capacity and differing arterial and venous tolerance during chronic isosorbide dinitrate therapy for conjestive heart failure. Circulation 1983;67:817-22.

23 Aronow WS, Lurie M, Turbow M, Whittaker K, van Camp $S$, Hughes D. Effect of prazosin vs placebo on chronic left ventricular failure. Circulation 1979;59:344-50.

24 Wilson JR, Ferraro N. Circulatory improvement after hydralazine or isosorbide dinitrate administration in hydralazine or isosorbide dinitrate administration

25 Wilson JR, Ferraro N, Wiener DH. Effect of the sympathetic nervous system on limb circulation and metabolism durnervous system on limb circulation and metabolism during exercise in

26 Coats AJ, Adamopolous S, Meyer TE, Conway J, Sleight P. Effects of physical training in chronic heart failure. Lance 1990;335:63-6.

27 Cleland JGF, Dargie HJ, Robertson I, Robertson JIS, Eas $\mathrm{BW}$. Total body electrolyte composition in patients with heart failure: a comparison with normal subjects and
patients with untreated hypertension. $B r$ Heart $J$ 1987;58:230-8

28 Markham RV, Gilmore A, Pettinger WA, Brater DC Corbett JR, Firth BG. Central and regional hemodynamic effects and neurohumoral consequences of minoxidil in severe conjestive heart failure and comparison to hydralazine and nitroprusside. Am J Cardiol 1983;52: 774-81.

29 Colucci WS, Williams GH, Braunwald E. Clinical, haemodynamic, and neuroendocrine effects of chronic prazosin therapy for congestive heart failure. Am Heart $J$ 1981;102:615-21.

30 Fifer MA, Colucci WS, Lorell BH, Jaski BE, Barry WH. Inotropic, vascular and neuroendocrine effects of nifedipine in heart failure: comparison with nitroprusside. J Am Coll Cardiol 1985;5:731-7.

31 Elkayam U, Weber L, Campese VM, Massry SG, Rahimtoola SH. Renal haemodynamic effects of vasodilation with nifedipine and hydralazine. J Am Coll Cardiol 1984;4:1261-7.

32 Rouleau JL, Warnica JW, Burgess JH. Prazosin and congestive heart failure: short and long term therapy. Am J Med 1981;71:147-52.

33 Riegger GA, Haeske W, Kraus C, Kromer EP, Kochsiek K. Contribution of the renin angiotensin aldosterone system to development of tolerence and fluid retention in chronic congestive heart failure during prazosin treatment. $A m \mathrm{~J}$ Cardiol 1987;59:906-10.

34 Cleland JGF, Dargie HJ, Hodsman GP, Ball SG, Robertson JIS, Morton JJ, et al. Captopril in heart failure. A double blind controlled trial. Br Heart J 1984;52:530-5.

35 Cleland JGF, Dargie HJ, Ball SG, Gillen G, Hodsman GP, Morton JJ, et al. Effects of enalapril in heart failure: a double blind study of effects on exercise performance, renal function, hormones, and metabolic state. Br Heart J function, hormo

36 The CONSENSUS Trial Study Group. Effects of enalapril on mortality in severe congestive heart failure. Results of the Cooperative North Scandinavian Enalopril Survival Study (CONCENSUS). N Engl J Med 1987;316:1429-35.

37 Agostoni PG, De Cesare N, Doria E, Polese A, Tamborini G, Guazzi MD. Afterload reduction: a comparison of captopril and nifedipine in dilated cardiomyopathy. $\mathrm{Br}$ Heart J 1986;55:391-9.

38 Mancini DM, Davis L, Wexler JP, Chadwick B, LeJemtel TH. Dependence of enhanced maximal exercise performance on increased peak skeletal muscle perfusion during long-term captopril therapy. $J$ Am Coll Cardiol 1987;10:845-50

39 Cleland J, Semple P, Hodsman P, Ball S, Ford I, Dargie H. Angiotensin II levels, haemodynamics and sympathoadrenal function after low-dose captopril in heart failure. Am J Med 1984;77:880-6.

40 Cleland JGF. Angiotensin converting enzyme inhibitors in congestive heart failure: first-line or second-line therapy? congestive heart failure: first-line or

41 Cleland JGF, Dargie HJ, McAlpine H, Ball SG, Morton JJ, Robertson JIS, et al. Severe hypotension after first dose of enalopril in heart failure. $B M J 1985 ; 291: 1309-12$.

42 Cleland JGF, Dargie HJ, Morton JJ. Effects of enalapril on diurnal variations in neuroendocrine and electrolyte status in heart failure. Cardiovascular Drugs and Therapy 1987;1:221.

43 Rouleau JL, Bichet D, Kortas C. Atrial natriuretic peptide in congestive heart failure: postural changes and reset with chronic captopril therapy. Am Heart J 1988;115:1060-7.

44 Cleland JGF, Gillen G, Dargie HJ. The effects of frusemide and angiotensin-converting enzyme inhibitors and their combination on cardiac and renal haemodynamics in heart combination on cardiac and renal haem

45 Cleland JGF, Dargie HJ, East BW, Robertson I, Hodsman GP, Ball SG, et al. Total body and serum electrolyte GP, Ball SG, et al. Total body and serum electrolyte composition in heart fail $J$ 1985;6:681-8.

46 Packer M, Medina N, Yushak M, Lee WH. Usefulness of plasma renin activity in predicting haemodynamic and clinical responses and survival during long term converting enzyme inhibition in severe chronic heart failure. Experience in 100

47 Packer M, Medina N, Yushak M. Efficacy of captopril in low-renin congestive heart failure: importance of sustained reactive hyperreninemia in distinguishing responders from non-responders. Am $J$ Cardiol 1984;315: 847-53. 